\title{
Erratum
}

\section{Erratum to "ERP evidence for conceptual mappings and comparison processes during the comprehension of conventional and novel metaphors" [Brain Lang. 127 (3) (2013) 484-496]}

\author{
Vicky Tzuyin Lai ${ }^{\mathrm{a}, \mathrm{b}, *}$, Tim Curran $^{\mathrm{c}}$ \\ ${ }^{a}$ Neurobiology of Language Department, Max Planck Institute for Psycholinguistics, Nijmegen \\ ${ }^{\mathrm{b}}$ Department of Psychology, University of South Carolina, Columbia \\ ${ }^{\mathrm{C}}$ Department of Psychology and Neuroscience, University of Colorado, Boulder
}

The publisher regrets the errors in Figs. 1-4 where a vertical line appeared at the top left corner of the figures in the published article. In addition, in Fig. 4A, the $Y$ axis of the red (dark red and light red) waveforms was repeated.

The correct images for Figs. 1-4 can be found here.
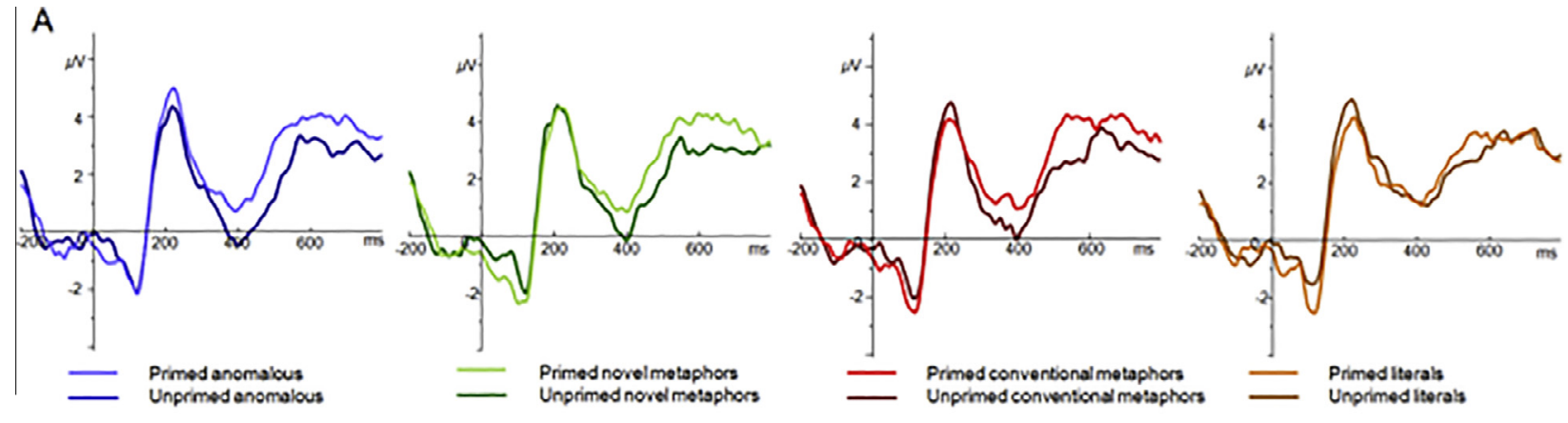

B
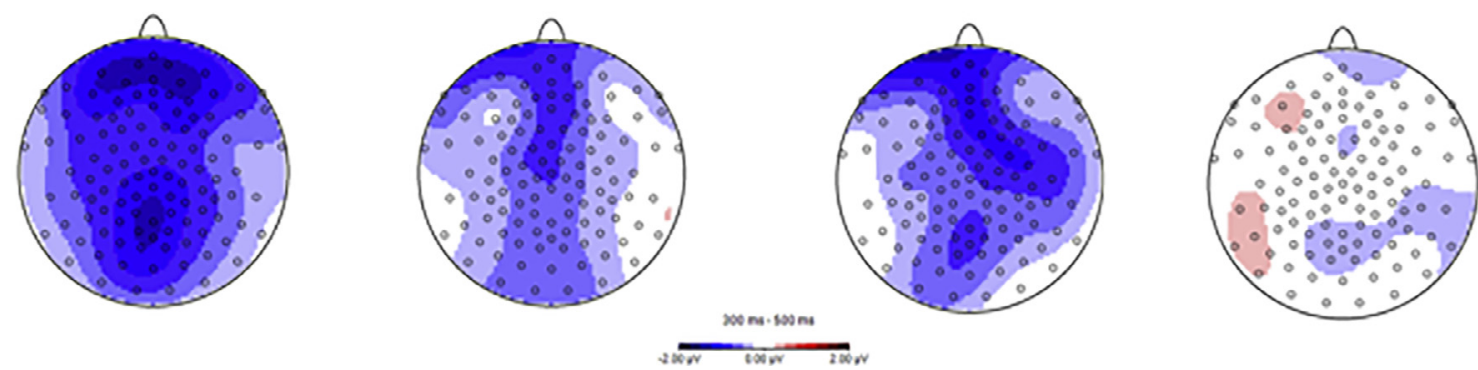

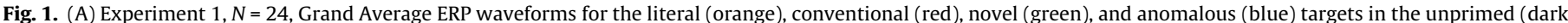

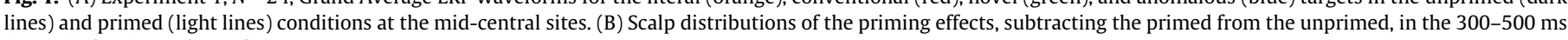
time window in each condition.

\footnotetext{
DOI of original article: http://dx.doi.org/10.1016/j.bandl.2013.09.010

* Corresponding author. Address: Department of Psychology, University of South Carolina, 1512 Pendleton Street, Columbia, SC 29208 , USA. Tel.: 803-777-4137.

E-mail addresses: vicky.tzuyin.lai@gmail.com (V.T. Lai), Tim.Curran@colorado.edu (T. Curran).
} 

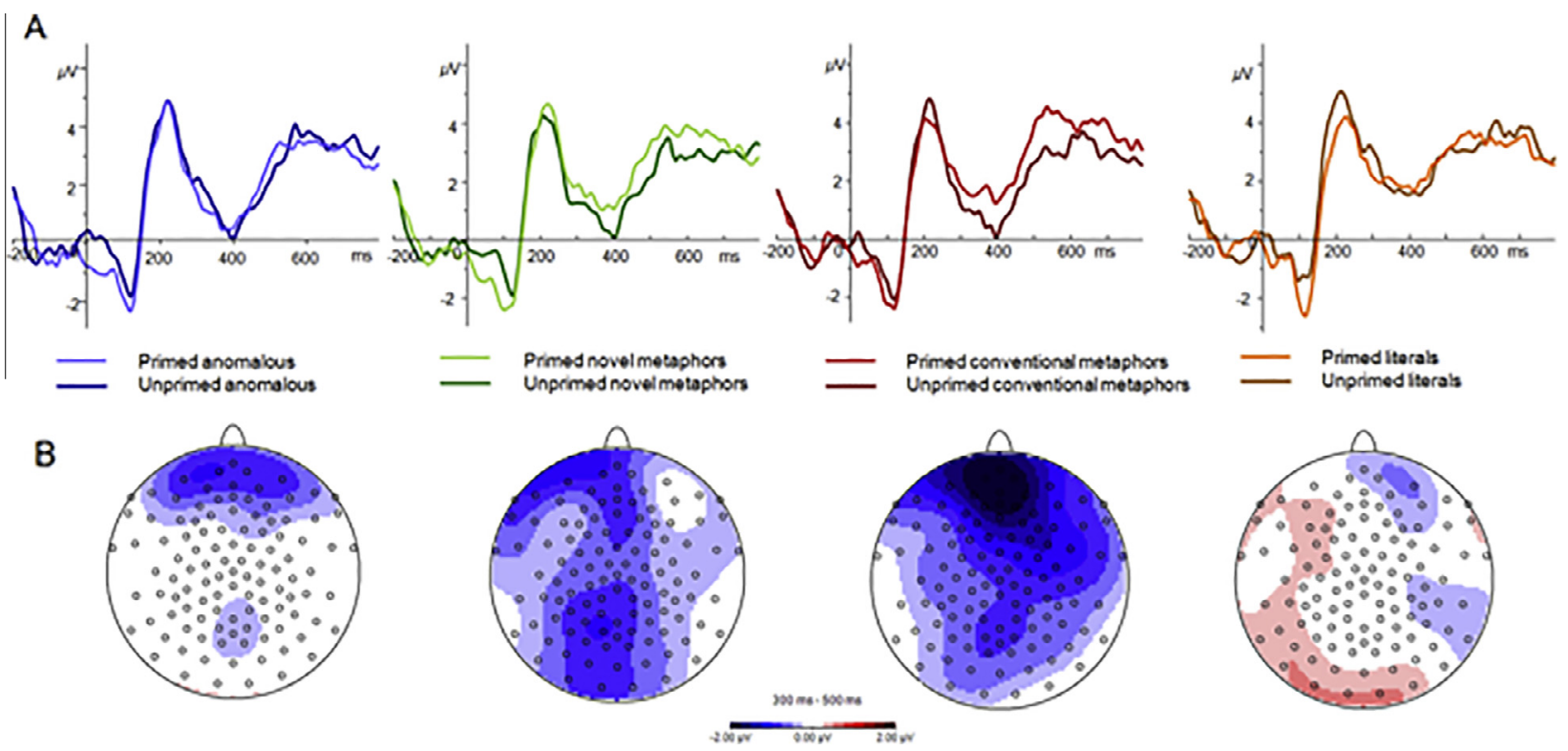

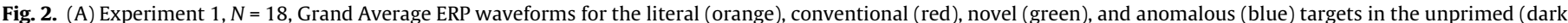

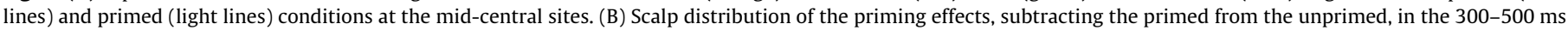
time window in each condition.
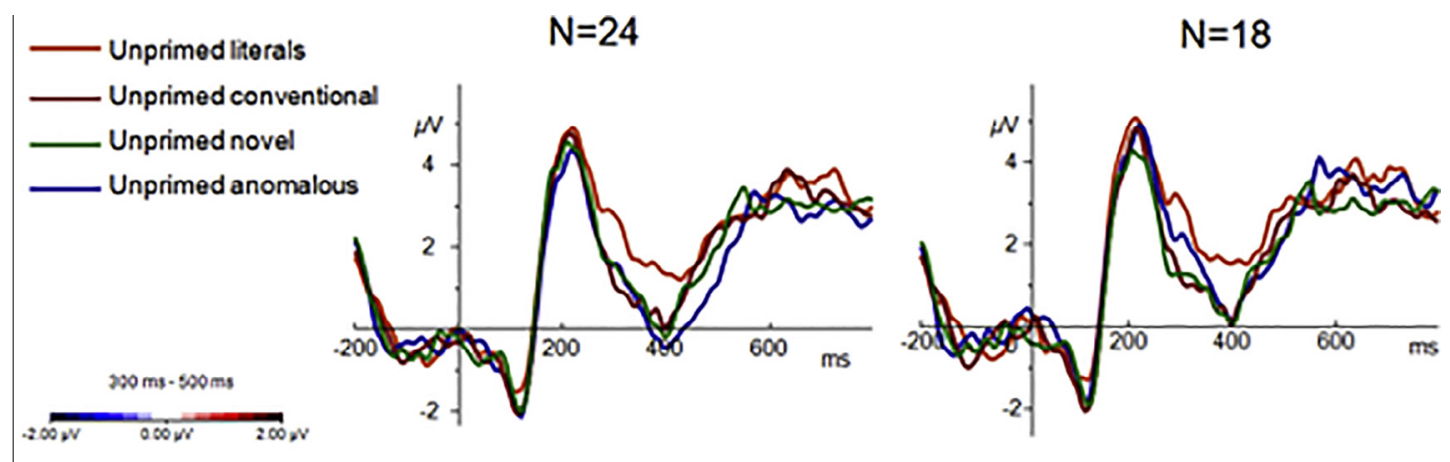

\section{Anomalous-literal}

Novel-literal
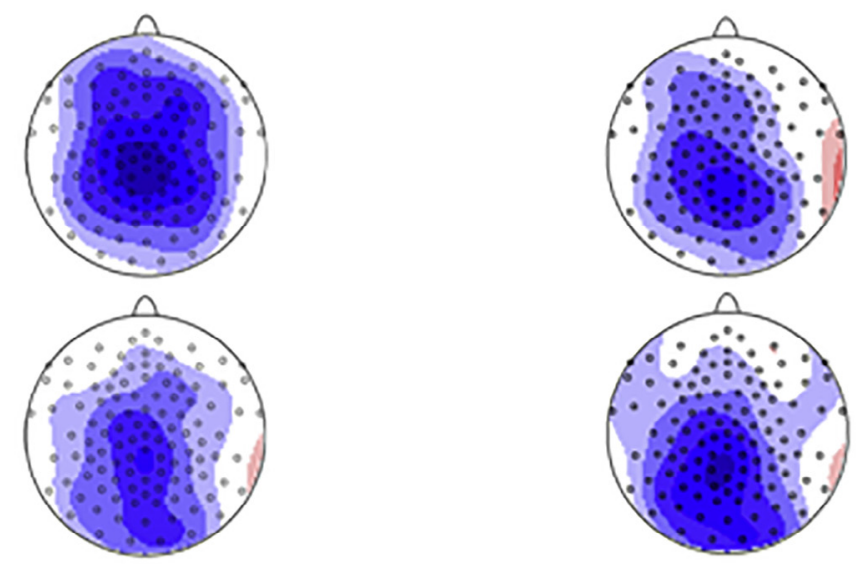

\section{Conventional-literal}
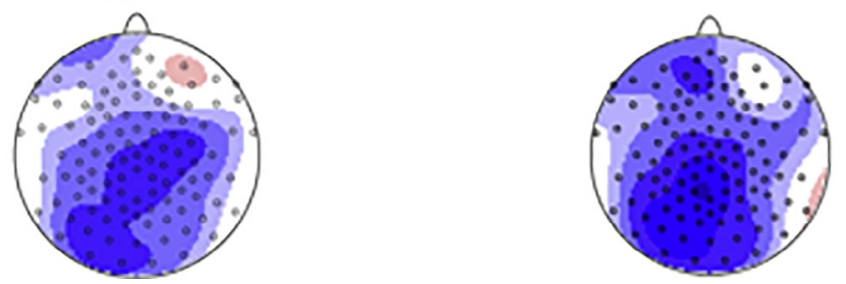

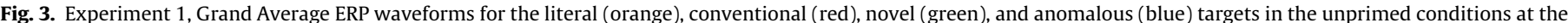

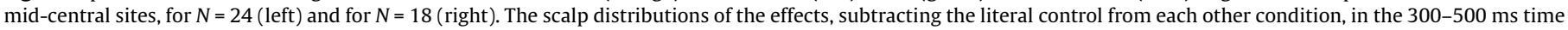
window, are displayed at the bottom. 


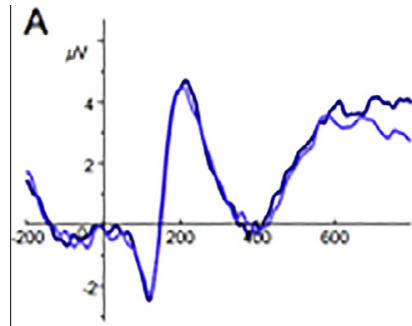

- Primad anomalous

B

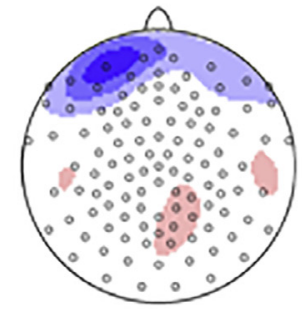

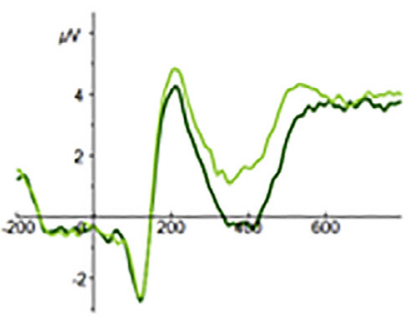

- Primed novel metophors Unprimed novel metophors

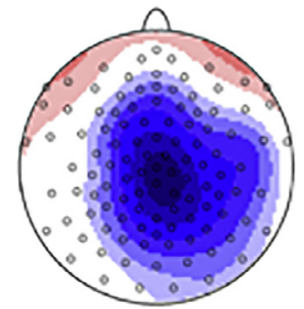

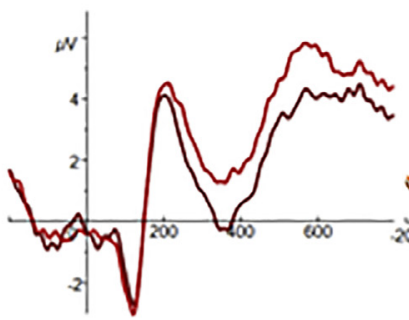

- Primed conventionsl metaphors Unprimed conventional metaphors

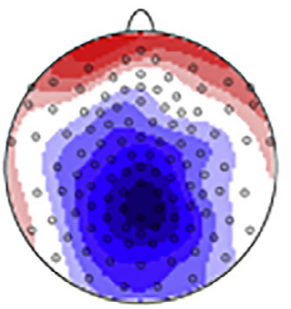

$300 m \cdot \operatorname{secms}$

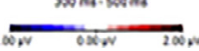

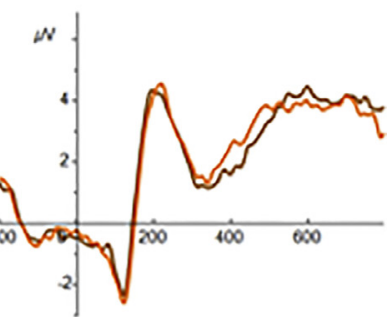

Unormedit

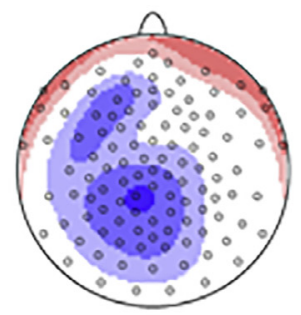

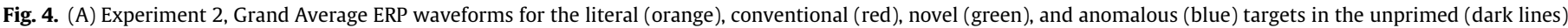

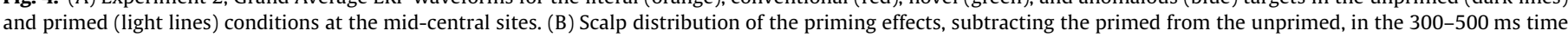
window in each condition. 